\title{
Interlanguage pragmatics: a study into the acquisition of pragmatic competence in English as a foreign language context
}

\author{
Anna Szczepaniak-Kozak
}

\begin{abstract}
In this chapter the acquisition of pragmatic competence in English among advanced Polish learners of English is investigated. A sample of linguistic written data was collected in a discourse completion task of an open response format, planned as the first stage of a longitudinal study on acquisitional pragmatics. The responses provided are analyzed in terms of their structure, taking into account not only the directness of the speech act itself but also the external and internal mitigation used. On this basis, conclusions about the interlanguage pragmatic competence of the participants are drawn. Also, selected aspects of L2 pragmatics which may require further instruction are discussed.
\end{abstract}

\section{Introduction: terms explained}

The aim of this chapter is to draw readers' attention to the importance of pragmatic competence, especially in classrooms or in contexts where two diverging politeness systems come into play. And as such it forms part of research on interlanguage pragmatics (henceforth ILP) in its narrow sense, i.e. "the performance and acquisition of speech acts by L2 learners" as defined by Ellis (2003:159 after Kasper / Dahl 1991). In particular the present author concentrates on a thorough description of problems which Polish advanced learners of English experience with formulating requests in the target language. The data analyzed in this chapter come from the first stage of a three year long study aimed at achieving an insight into their ILP development. The overall research question of the study is whether classroom settings will afford these EFL learners a repertoire of situations facilitating an increase in this competence in the area of selected speech acts.

It has become a cliché almost that interlocutors who do not share the same politeness systems because they, for example, come from cultures or societies based on different values may encounter cross-cultural misunderstandings. What aggravates the situation is that while phonological, syntactic, or lexical errors made by non-native speakers are normally regarded as signs of a low command of the L2 and turned a blind eye to, pragmatic inadequacy is frequently interpreted as rudeness by native speakers, which in consequence either leads to

Szczepaniak-Kozak, Anna (2014). "Interlanguage pragmatics: A study into the acquisition of pragmatic competence in English as a foreign language context". In: Adamczak-Krysztofowicz, Sylwia and SzczepaniakKozak, Anna (eds). Kultur-Kommunikation-Kreativität-Reflexivität. Aktuelle Beiträge zum universitären Fremdsprachenunterricht. Peter Lang: Frankfurt a.M. 59-76. 
or strengthens mutually unfavorable stereotyping (Sabaté i Dalmau / Currel i Gotor 2007:288) if not incurring aggressive reactions.

\section{The methodological background to the study}

In this chapter I intend to investigate preliminary data on the interplay between L2 linguistic proficiency and the acquisition of pragmatic competence among advanced Polish learners of English, collected with the use of a discourse completion task (DCT). Despite the well-known weaknesses of the discourse completion task ${ }^{1}$, it is recognized as a reliable and effective method of data collection in pragmatic studies, e.g. Blum-Kulka et al. (1989), Rose / Kasper (2001), Ogiermann (2009a and b), and Ellis (2003). It is especially appreciated for its 'discreteness' which according to O'Keeffe et al. (2011:22), means that "the researcher has a lot of control over the language which they want to elicit. The focus can be limited to a very specific context of use [...]".

As mentioned above, a sample of linguistic written data was collected in an open response format DCT, planned as the first stage of a longitudinal study on acquisitional pragmatics. Its participants, i.e. 57 first year BA students of bilingual philology studies at Adam Mickiewicz University in Poznań, Poland, had not received pragmatic instruction prior to the data collection. At the time of the sample collection (October, 2011) they were in the first weeks of their studies. They are advanced students of German and English who receive around 25 hours a week of instruction in those foreign languages as a long-term preparation for the profession of translator, teacher or intercultural mediator. Their assumed proficiency level is at least B2. In order to monitor their assumed development of pragmatic competence, they were given the same task in their second year of studies (November, 2012) and are to be given it one more time before their graduation in June, 2014.

The present study was inspired by Bardovi-Harlig's (2001:14) statement that students of high grammatical proficiency needn't develop "concomitant pragmatic competence" and they may differ not only in their pragmatic competence but also in the tempo and success of its development. As extensive research on pragmatic failure shows, non-target-like performance is common not only among students with low proficiency in the target language, but also among advanced language learners presenting a good command of grammatical and lexical elements (Bardovi-Harlig / Hartford 1990).

The data collecting instrument was adapted from Liu (2007), who devised a Multiple-Choice Discourse Completion Test (MDCT) to assess Chinese students' pragmatic competence. In order to test their ability to judge the

I discuss it in Szczepaniak-Kozak (in press). 
appropriateness of particular responses in communication situations, he devised a test including 24 speech act scenarios followed by three response alternatives to choose from. I decided to take advantage of some of Liu's (2007:395-404) questionnaire situations because they were painstakingly developed, taking into account differing social variables such as power status, distance and degree of imposition. Additionally, Liu applied pilot studies and interim testing procedures to strengthen the reliability and validity of his measure. However, the samples provided by the Polish students were not evaluated against the responses given and validated as correct by native speakers of English as was done in Liu's study. This is because my intention was to extract the national trend, rather than to contrast the samples with native use, in order to avoid a normative or evaluative approach to L2 production. In the present chapter only two selected test items are discussed due to limitations on space.

I also follow Bardovi-Harlig's (2001:14-15) research paradigm to investigate whether Polish speakers of English differ in performance/nonperformance and realization of the speech act of requesting from native speakers of English. Where the same speech act is chosen, they are analyzed mostly in terms of their structure, taking into account not only the directness of the speech act itself but also the external and internal mitigation used. For that purpose, models of analysis designed by Blum-Kulka (1987:133134), Blum-Kulka et al. (1989:1-34, Appendix), Spencer-Oatey (2000:24-27), Rue / Zhang (2008:52-57; 313-314), Takahashi (2001:199) and Bardovi-Harlig (2001) were combined. All examples are provided in their original form.

\section{Polish requests}

Requests can be very generally defined as directive speech acts which are performed to make the hearer do something beneficial for the speaker. The peculiarity of this speech act lies in the fact that both the hearer and the speaker realize that the hearer may refuse to do what is asked of them. Requests are very much rapport sensitive, because their semantic components and face-threatening potential will depend on the intimacy between the speaker and the hearer, the power relations between them and the degree of conventionalization. This is why most requests call for the use of strategies of negative politeness, i.e. external mitigation, differing levels of head act directness or syntactic/lexical downgraders or upgraders.

Differences in requesting strategies in English and Polish have been studied, for example, by Wierzbicka (2005), Lubecka (2000) and recently by Rakowicz (2009). The present study is based on the assumption that obvious differences 
between Polish and English cultural norms, and the characteristics of these speech communities, condition differences in requesting strategies applied by native speakers of a particular language. Thus, English native speakers employ requesting strategies depending heavily on the use of the interrogative, and avoid the use of the bare imperative. Polish native speakers, on the other hand, also use interrogatives to convey a request. This has been shown to be valid in studies conducted by Kalisz (1993:112-113), Ogiermann (2009 a, b), and especially where interlocutors do not know one another (Marcjanik, 2009:6465). However, Wierzbicka (1985) and Lubecka (2000) emphasize the role of the imperative in performing Polish requests in informal situations. In Lubecka's (2000:75-76, 85) all-encompassing study, direct orders constituted $25.3 \%$ out of the 254 requests she collected. However, according to Marcjanik (ibid.), ability questions are the most polite request realizations among all the interrogative constructions available for the performance of requests in Polish. Formality and informality are also marked by pronouns (you, $I$ ) which point to the hearer's or speaker's role in performing the request. In most cases verbs in the first person singular express a more informal relationship between speakers than verbs in the second person (Marcjanik 2009:65; Ogiermann 2009a:210). Another mitigating internal device in Polish is negation of the head act, which expresses the speaker's uncertainty about the potential success of the request, thus softening the imposition (Ogiermann 2009a:200; Lubecka 2000:113). In Lubecka's research, conducted in the late 1990s, $47 \%$ of all requests and invitations were in a negated form. This uncertainty can be strengthened in Polish by adding the downtoner może (perhaps), czasem or przypadkiem (happen to or by any chance) (cf. Marcjanik 2009:64-65). All in all, both Marcjanik (2009:64) and Ogiermann (2009a:211) suggest that Polish does not rely as heavily on the imperative as claimed in the previous research.

Due to the differing request strategies in these two languages, it is assumed in the present study that when Polish native speakers learn English, they need to overcome problems related to negative language transfer from their mother tongue in the area of interlanguage pragmatics. Possible areas of difficulty are: the appropriate selection and use of interrogative and imperative request forms, presence, form and variety of internal/external modification, together with the degree of formality and directness applied.

\section{Data analysis}

Below, a comparative analysis of the responses provided to two request situations are presented. In the first situation, namely the $6^{\text {th }}$ item in Liu's (2007) 
test, the tested relationship was that of a student in interaction with an unknown student. The scenario puts the student into a situation where he or she asks an unknown student to stop blocking his or her view during a basketball match. Here the power status of the participants, who do not know each other, is equal, and the imposition of the request is moderate. Most importantly, the speaker clearly has the right to pose the request but the satisfaction of the request depends on the discretion of the other student, but not much convincing on the part of the speaker is required.

Another scenario, the $12^{\text {th }}$ item in Liu's (2007) test, takes place during a workplace meeting where a manager asks a colleague to lend him some paper. They know each other very well, but the person making the request is a manager, so presumably they are not equal in the workplace hierarchy, but the imposition of the request is low and not much convincing would be required. The situations were worded as follows together with the routine selected as the most appropriate by anonymous native speakers as reported by Liu (2007: 391-415):

Situation 6: You are watching a basketball game. A student you don't know comes and stands just in front of you blocking your view. You want to ask the student not to block your view.

Exemplary appropriate request: Sorry, you are blocking my view, would you please take another place?

Situation 12: You are the manager of a company. You are in a meeting with the other members of your company. You need to write some notes, but realize you do not have any paper. You turn to the person sitting next to you. You know the person very well.

Exemplary appropriate request: Have you got some extra paper?

Initially the gathered data were quantitatively and qualitatively analyzed. Once this initial selection is made, the analysis takes into account whether and what type of alerters, external mitigation and lexical downgraders and upgraders are used, together with naming the strategy types for making requests. In this way, it was possible to study how the participating students intensify their requests, in terms of both the degree of intensification applied and also the lexical choices made by them in order to do so. Also external mitigation is taken into account.

External mitigation devices do not affect the utterance used for realizing the act but rather the context in which it is embedded, and thus, indirectly, they modify the illocutionary force of a particular speech act. This type of mitigation takes place in the form of supportive moves occurring either before or after the head act. There are mitigating and aggravating supportive moves. Supportive moves which accompany the head act and modify its impact by softening 
(downgrading) it are called mitigating, and those inflaming (upgrading) the imposition of the act are called aggravating ones.

While classification of and research into mitigating supportive moves is well established and known, there has been scant discussion and research on aggravating devices. In this particular paper the author follows the following categorization of aggravating moves which is based on Blum-Kulka et al. (1989:1-34), Zhang (1995) and Sweeny / Hua (2010). All of them could be labeled genuinely impolite and the ones described below are based on negative impoliteness strategies:

Threats - which imply that action detrimental to the hearer will take place if the request is not satisfied;

Reprimands - which express scorn for some aspect of the hearer's behavior; Moralizing - which pledges the hearer's adhering to widely accepted rules of good behavior and maintaining personal integrity;

Aggressive interrogatives - emphasize, for example, the speaker's social position, they may also ridicule or challenge the hearer's person, behavior or previously stated words.

\section{Situation $6^{2}$}

Not all students were able to provide a request for this scenario, i.e. three students left this task unanswered. The remaining 54 answers were requests which asked an unknown student to change his place and enable the student who passes the request to watch a basketball game. There were only few responses that resembled the structure of the exemplary answer, i.e. alerter + grounder + query preparatory. Example 1 is one of the responses that were close to it.

Ex. 1. Sorry, but I don't see anything so could you stop blocking me a view please?

\section{Alerters}

Using an alerter in this particular scenario would be natural, as here the unknown student sits or stands with his back to the student who makes the request, so some form of attention gainer is necessary. Altogether there was one, sometimes double or triple, precursor in 39 samples. Apart from the apologetic formulae Excuse me (17) and Sorry (7) there appeared informal alerters, in most cases greetings: Hey (6), Hi (2) and Hello man (1), You in front (1). When we compare these data with, for example, the alerters provided in scenarios 3 and 11, where the students found

2 All examples are quoted in their original wording. 
themselves in conversations with teachers whom they addressed with vocative names and titles, it is clear that the students are competent in applying an adequate degree of formality when it comes to selecting alerters.

\section{External mitigation}

As already mentioned, even a cursory examination of the collected data reveals that the students selected from the repertoire of both supportive moves (mitigating and aggravating), and thus the impositive force of the request differed considerably from sample to sample. This could have occurred due to individual preferences in speech act realization or developmental differences in a particular student's interlanguage. Furthermore, some of the students might have wanted to make the addressee realize the seriousness of the situation by aggravating the illocutionary force of this request. Although, when evaluated objectively, this is doubtful as this request's illocution is to ask a stranger to change his seat. This could also be explained on cultural grounds.

Out of the 70 supportive moves 16 were of the aggravating type, mostly reprimands (11; ex. 2), with few expressions of moralizing (2; ex. 3) and aggressive interrogatives ( 3 ; ex. 4). Most interestingly, in other requestive scenarios in this discourse completion task, aggravating mitigation moves were rare or not present at all.

Ex. 2. Hey, you're staying in front of TV and I'm trying to watch the match. Can you seat on something?

Ex. 3 Stand on the right. I don't see anything. It's unfair.

Ex. 4. Excuse me, do you think you are invisible? Would you like to take a seat next to me?

It needs be admitted that sometimes it is difficult to assess what function a particular response collected in a discourse completion task plays. This is because some of the reprimands collected could also be classified as grounders (ex. 5). I decided to classify this move as a reprimand because stating the obvious (watching a basketball game) serves the purpose of guiding the hearer to see what everybody should know (showing that a person does not know something obvious stands for telling the person that he or she is not mindful or concerned).

The remaining supportive moves were of the mitigating type, most of which were grounders (46; ex. 6), 65\% in total. This coincides with the results of other studies in this area. Grounders have appeared in numerous studies on requests as the dominating category. Their relatively high frequency is considered indicative of "the estimated necessity of justifying the intrusion upon the hearer's face in a given 
culture" (Ogiermann 2009a:2010). Providing an explanation why it is necessary to impose on the hearer makes the activity more justifiable and by doing so makes the hearer more eager to perform the requested activity. The remaining mitigating moves were apologies I am (so) sorry (7) and one gratitude move Thanks.

Ex. 5. Hi, I am watching a basketball game. Please, don't blocking me view.

Ex. 6. I can't see anything. Could you change your place?

Altogether, we get a very clearly distributed sample with aggravating moves on one side and grounders on the other with just two more types in between. The observed nonvariabity in such an imposing situation might indicate that some speakers chose impoliteness strategies while others tried to soften the imposition by providing a reason or justification of the act, thus saving the positive face of the hearer. This could also be explained by taking into account what Ogiermann (2009b:31) writes about Poles in contact with strangers. When the social distance between speakers is considerable, Poles prefer anonymity "evidenced by lack of greetings, smiles or even eye-contact", which is interpreted by other nations as aggression, lack of manners or disrespect. In the present data I can clearly see a marked difference between pragmalinguistic forms produced in situations characterized by polarized degrees of social distance. In other words, the Polish students choose different external moves and different politeness strategies depending on whether the addressee is a stranger or friend. This is aptly captured again by Ogiermann (2009b:31-32), "the variable of social distance [...] allows for a greater discrepancy than in Anglo-Saxon culture" in the performance of speech acts depending on whether Poles perform it in the public or private sphere. In public they may seem demanding, pushy, distant or simply rude.

What needs to be added is that grounders constitute the most numerous category throughout the whole corpus of scenarios. For example (SzczepaniakKozak in press) in the data collected in the $3^{\text {rd }}$ scenario, in which a student asks a teacher to speak slowly during their discussion of the student's assignment, there were 62 external mitigations and grounders constituted the dominant type (43; $69 \%$ ) often accompanied by apologies (14). And in the $11^{\text {th }}$ scenario, where a student asks the president of the university, whom he or she knows from previous classes, for an interview on a topic related to his or her graduate thesis, the category of grounder was used 37 times in a sample of 92 external mitigating devices $(40 \%)$.

Requestive acts

The speech acts of requesting collected in the present corpus were analyzed in terms of their level of (in)directness following the classification proposed by Blum- 
Kulka (1987:133-134), Blum-Kulka et al. (1989:18) and Takahashi (2001:199). (In)directness in this context stands for "the relative length of the inferential path needed to arrive at an utterance's illocutionary point" (Blum-Kulka 1987:133).

Out of the 54 requests provided, starting from the most direct strategies, there were eight mood derivables (ex. 7), 38 query preparatories (ex. 8), one permission question, one mitigated-preparatory statement (ex. 9) and three mitigated-want statements (ex. 10). In the present sample there were also three examples of non-conventionally indirect request (ex. 11, 12 and 13) classified as strong hints. There were no examples of the most direct strategies where the requestive force is marked by Illocutionary Force Indicating Devices (IFID). Ogiermann (2009a:192) suggests that the possibility of achieving some desired object or action without explicitly asking for it, "has led some researchers to suggest that requests are dispreferred actions, their preferred variant being an offer or compliance with the pre-request". She continues by saying that complying with a non-overt request can be viewed as more polite and less imposing. However, the utterances in examples 11, 12 and 13 could not be labeled polite because, according to Blum-Kulka et al. (1989:19), "avoidance to name the hearer as actor can reduce the form's level of coerciveness", but my examples include the pronoun you.

Finally, it is worth mentioning that one student performed two speech acts (ex. 14), both of which were externally and internally mitigated mood derivables. This is an example of verbosity (over-informativeness) as a strategy in interlanguage pragmatics. Verbosity has been defined by Levenston (1971) as a phenomenon when speakers provide more information than necessary, when they are over-explicit, thus violating Grice's maxim of quantity.

Ex. 7. Please do not block my view, because I'm actually watching this basketball game.

Ex. 8. Could you move a bit. I can't see anything!

Ex. 9. Excuse me. I would like to know, if you has nothing against moving a few steps to one of the sides, because I don't see anything.

Ex. 10. Hello, I can not see anything, cause you are standing right in front off my face. I'd be grateful, if you could move a little bit.

Ex. 11. Excuse me, I'd love to watch this match till the end but you're standing in front of TV and interrupting me.

Ex. 12. Hello, excuse me. I'm watching this. Hello! You're blocking view, it's really rude!

Ex. 13. Sorry but you aren't the one who is watching the basketball game now.

Ex. 14. Excuse me, I'm watching a match. Don't stay in front of me please, because I don't see anything. So if it's possible stay near. 
The results of my analysis partially overlap with the research data and conclusions of Ogiermann (2009 a and b). Both my data and hers clearly show that interrogative constructions constitute preferred strategies both in Ogiermann's sample of Polish requests (75\%) and my corpus of interlanguage requests in English. Contrary to Wierzbicka's (1985) suggestions, and at some points Lubecka's (2000), despite the fact that the English system of interrogatives forms employed for requests is indeed more developed, it does not mean that the limited Polish repertoire is made up for by the imperative mode (mood derivables). Both in Ogiermann's data and mine, mood derivables appear but not so frequently, i.e. $20 \%$ in Ogiermann's data and $15 \%$ in mine. Likewise Kalisz (1993:110-112) disproves Wierzbicka's (1985:151) statement that out of the fourteen interrogative forms which can be used to perform the speech act of a request, not a single one can be translated into Polish. Kalisz (ibid. 111) presents numerous examples to counterargue her idea on two levels, i.e. that the Polish system is less developed and that "Polish expressions of this kind sound formal and are overpolite, displaying uncertainty on the speaker's part concerning the addressee's fulfilling the request". When we assume that the Polish system of the interrogative is as productive as the English one, there is a huge potential for these forms to stimulate a positive transfer of request forms from L1 (Polish) to L2 (English), which is already noticeable in my data of the interlanguage pragmatics.

\section{Internal mitigation}

Internal mitigation devices are "elements within a head act which are not essential for its understanding (Blum-Kulka et al. 1989, Appendix). They come in two types, depending on whether they soften the message, which is the function of downgraders, or intensify it, which is the function of upgraders (Sweeney / Hua 2010:486-7). The repertoire of downgraders is extensive: interrogative constructions, tenses, conditionals, negated sentences, lexical downtoners (politeness markers, understaters, hedges, idefinite pronouns, cajolers, consultative devices, etc.). As far as upgraders are concerned, the imposition of a request can be strengthened by intensifiers, expletives or time intensifiers.

Generally, in my data the respondents displayed an underuse of lexical/phrasal downgrading or upgraders. There was not much syntactic variation in internal downgraders either. According to Economidou-Kogetsidis (2009:93), so formulated interlanguage requests may have a distorted, nonnative-like pragmatic effect, coming across as abrupt or as being insufficiently mitigated. 
Most often there were ability questions formulated with the past simple tense could with a very low frequency of conditional constructions (2; ex. 16) and no negated interrogatives. The high frequency of ability questions in the past tense (26; ex. 15) is not surprising. This construction is, according to Marcjanik (2009:64) and Ogiermann (2009a:199), the dominant category in Polish. Thus, it was easier for these learners of English to master this aspect of pragmatic competence in English due to positive transfer (Selinker 1972, Ellis 2003) from the Polish language. In other words, here we observe a facilitative effect of their native language on the acquisition of requests in the target language. However, the case is different with thirteen ability questions formed with the present simple tense can, which would be considered the marked form in contrast to the requests with could.

Ex. 15. Sorry buddy, could you sit down somewhere, you are blocking my view.

Ex. 16. I would be grateful, if you could move a little bit.

Although English to a broad extent uses consultative devices, in my data there were no examples of such downgraders. Instead, in my data adverbials of place dominated, which is a natural consequence of the fact that this request asks a stranger to change his or her place. The second most frequent category was the understater a little bit (13) or a few steps (2). This is probably a significant issue because when we realize that generally these students do not use very many downgraders or upgraders and they are not very varied, the fact that there is a strong preference for some downgrading strategy means that at that level of their proficiency these two might be the first to be acquired. Interestingly, in Ogiermann's (2009a:210) data Poles and Russians relied more on syntactic downgrading, such as tense and negation. Additionally, another of her conclusions is that "there is a strong preference in Polish for formulaic preparators and a lower frequency of politeness markers". While prosze (the most frequent politeness marker in Polish) is a rare occurrence in Ogiermann's data (out of her corpus of 100 Polish requests there were only three requests that used prosze), in my interlanguage data, please appears 10 times, which constitutes another proof of these learners' developing interlanguage. However, my data support another conclusion of Ogiermann concerning that politeness marker. Namely, Ogiermann (2009a:203-204) puts forward that a lexeme expressing what please does in English is present in many languages but languages differ in positioning it within an utterance. According to her, in English please is most often classified as an internal modifier whereas in Polish it is always external, i.e. Polish prosze cannot occur in the head act because it is a performative verb in itself. Indeed, in nine out of the ten requests collected for 
this requestive situation please was positioned at the beginning or end of the speech act (ex 17) rather than internally (ex. 18), which could be considered a negative transfer form Polish. Additionally, the pattern shown in example 17, i.e. a mood derivable preceded by please, is a very frequent request realization in Polish, the students' native language, and, according to House and Kasper (1981), also in German (bitte), i.e. the students' third language. Hence, here their developing interlanguage pragmatic competence might be impacted by two languages: Polish and German.

Finally, the remaining categories of internal mitigation were: one syntactic downgrader (aspect) I would like you to, three cases of giving option with or, one intensifier really, eight indefinite pronouns some, which could be classified as hedges, two downtoners and one appealer.

Ex. 17. Please go right or left.

Ex. 18. Could you please not block my view?

\section{Situation 12}

All 53 responses provided were requests for paper to make notes in a typical workplace interaction (meeting) between two colleagues, one of whom is probably the manager of the other. Four students did not give any answer. Generally, the responses were short in comparison to, for example, the above analyzed situation 6 . To perform the cued speech act in scenario 6 , the students used around 17 words, and in the present scenario an average sample was 11 words. This might mean that the students are already sensitive to the degree of conventionality and informality which particular situations evoke and that they form their responses taking into account sociocultural background given in the description.

\section{Alerters}

This economy of words is also visible in the alerters used. Altogether there were 28 alerters, most of which were address terms. In the majority of cases the students chose the first name to indicate the fact that here two work colleagues are involved. For this purpose 14 familiarized first names are used, something not observed in the other scenarios. This sociocultural sensitivity and the ability to use pragmalinguistic means to express it is further noticeable in 14 examples of $h i$ and hey in the utterance initial position serving the function of an informal greeting. According to Halliday and Hasan (1985:63), greeting indicates continuity of personal relations, and signals the recognition of the other participant as a potential agent in some activity. 


\section{External mitigation}

The students' developing pragmatical competence is discernible in the fact that the number, and types of external supportive moves is reduced. In the former scenario there were 70 mitigation devices of six types. Here the repertoire is limited: only 34 external mitigation devices of four types were provided. There were no aggravating moves. As in other scenarios of this DCT, the grounder is the type which is most often used (30; ex. 19). However, even if in this scenario we have a slight power asymmetry, i.e. this is most probably an exchange between a manager and his or her work colleague, the imposition is very low because this is a typical conventionalized workplace request which most native speakers would realize without any mitigation. In fact, Polish speakers would do the same in Polish. Additionally, this request is performed either downwards (to a subordinate) or horizontally (to a colleague equal in position) so more directness and less mitigation are observed both in Polish and English. However, these students assumed that some justification for the request is necessary, which in a naturally occurring situation would be redundant or unusual. The remaining types of mitigation moves were: two expressions of gratitude (ex. 20), one preparatory (ex. 21) and one apology.

Ex. 19. Please give me some paper, because I haven't and I have to do some notes.

Ex. 20. Excuse me, I forgot paper, so i have any. Could you borrow me some paper? I'd be thankful.

Ex. 21. Hey, Mark, do you have any spare paper, by chance? I didn't take any with me. Could give me a couple of sheets?

\section{Requestive acts}

In this sample of 53 requests there were, again starting from the most direct strategies: 12 mood derivables (ex. 22), 26 query preparatories (ex. 23), 10 permission questions (ex. 24) and five strong hints (ex. 25). Clearly the query preparatory was the most frequently chosen structure in the situation where the imperative would be the unmarked construction due to its greatest directness and least politeness. This dominance supports the assumption that at this stage of their pragmatic development in the target language the students' preferred request strategy is an interrogative sentence with you, despite the sociocultural context of the situation in which the request is performed. Also the appearance of strong hints, request strategies, which are considered indirect speech acts high 
on the politeness scale in English (Blum-Kulka 1987:137), would call for classroom instruction and practice.

Ex. 22. Give me some paper, ok?

Ex. 23. Sorry, can you give me some paper?

Ex. 24. Sorry but I forgot my notebook. Could I use some of your paper?

Ex. 25. Do you have a spare sheet of paper? I don't have any.

Internal mitigation

In this scenario the students exhibited a rather restricted pragmatic repertoire of internal modifiers in their production. Zero marking, which would probably characterize native speech, was frequent here as well. Additionally, the indefinite pronoun some (in 26 samples) together with two understaters $a$ few and small, both serving the same function of softening the force of the message, were the most frequent modifiers. The politeness marker please appeared ten times (only three times internal to the head act). The remaining categories of internal mitigation were represented by single examples, e.g. appealer, intensifier, giving option, or not represented at all. The striking disproportion between the number and variety of internal and external mitigation might support what Economidou-Kogetsidis (2009:102) noticed in interlanguage pragmatic competence of her Greek learners of English:

external modification in the form of supportive moves is acquired by learners quite early on, probably due to the fact that external modifiers, unlike internal modifiers, do not require knowledge of idiomatic (i.e. native-like) use and they simply involve the construction of a new, often syntactically simple clause. As such, external modifiers tend to be syntactically less demanding and pragmalinguistically less complex.

In general, I would agree that when we consider which norms these non-native speakers of English should target, in order to avoid negative attributions, some measure of convergence with the pragmatic rules of English are desirable. However, a total convergence of the two pragmatic systems involved is probably unattainable and undesirable. This is so because some pragmatic distinctiveness enables these non-native speakers to assert their identity, although at this stage of their interlanguage pragmatic development they probably do not realize it (Kasper / Schmidt 1996:156).

\section{Conclusions}

As to the positive transfer in the present data, the students have already mastered the rules of greeting in English. This is visible in the fact that they use different forms for scenario 6 and 12. In the scenario involving strangers they use Excuse 
me, or Sorry and in Scenario 12 they start their response with familiarized first names or informal greetings ( $\mathrm{Hi}$ or Hey).

On the basis of the above analysis it is also possible to suggest that the request strategy which the students use most often is the interrogative (query preparatory) and not the imperative (mood derivable). This would support Kalisz's (1993:111) critical comments on the validity of Wierzbicka's (1985) ruminations on the use of interrogative in Polish for requests. My data, if constituting a limited corpus, demonstrate that due to the positive transfer from L1 these Polish students have already acquired the use of query preparatory to convey the speech act of a request in the target language. This is certainly a positive transfer because in a contrastive study on requests in Polish and American English conducted by Lubecka (2000) out of her Polish corpus of 508 requests and invitations $58.2 \%$ per cent were Conventionally Indirect Standardized Requests and Invitations (CISRIs). In the same corpus direct orders constituted a quarter of all requests and invitations in her corpus (25.3 $\%)$. By comparison, in her corpus of American data CISRIs constitute a comparable part, i.e. $61.1 \%$, with a slightly smaller but still comparable share of direct orders, i.e. $18.4 \%$. However, it needs to be added that although Lubecka's research results show an invaluable, state-of-the-art scientific endeavor, it is difficult to directly juxtapose her data with mine due to the way her data are categorized. She clearly decided at some point of her analysis to combine several categories into one, which makes it more difficult to extrapolate frequencies of use for particular subcategories of her analysis. For example, she combines requests and invitations into one research category, and does the same for questions and declarative statements, without providing statistical data for her sub-repertoires. Finally, this study reveals that the students, at this stage of their interlanguge pragmatic development, use the query preparatory in a situation (Scenario 6) which demands a more direct strategy, e.g. the mood derivable. This might imply that, on average, they are not able to select the appropriate strategy for a particular situation but rather prefer one strategy to others and apply it across all scenarios.

Quite interestingly, a number of learner requests combined the politeness marker please with a quite direct strategy (e.g. mood derivable or want statement) instead of using a query-preparatory strategy typical of English native usage. This may be indicative of their interlanguage, a feature which also Economidou-Kogetsidis (2009:92-93) found typical of Greek learners of English.

The appearance of grounder as the most typical supportive move proves what other studies on native and non-native requests have proven, i.e.: 
that giving reasons, justifications and explanations for an action opens up an empathetic attitude on the part of the interlocutor in giving his or her insight into the actor's underlying motive(s), and is thus an efficient mitigating strategy with a wide range of applications (Faerch / Kasper 1989:239).

It may be speculated that these students intuitively assume that when they give a reason for their request, their hearer may more eagerly respond positively to it. Additionally, the multiple external mitigation observed in the data collected for Situation 6 support other research results on the acquisition of pragmatic competence, i.e. that learners of English use more external mitigation devices than native speakers do, e.g. Kasper (1981, after Economidou-Kogetsidis 2009), Faerch / Kasper (1989). The reason for that might be the fact that external mitigation is acquired early on, and is preferred because such moves are more explicit in their politeness function. Finally, at least in the present study, it has been noticed that more supportive moves were used when indirect acts are used, i.e. direct head acts are less externally mitigated.

The analyzed material also allows us to suggest that these particular English learners rely on a small set of formulas and lexical devices to internally modify speech acts. They all used some syntactic and lexical downgraders but they were not very varied. At this stage of their interlanguage pragmatic competence development they cannot apply linguistic resources with native like appropriateness either. It has been argued in other studies that "internal mitigation is particularly sensitive to level of proficiency and is part of a late developmental stage" (Economidou-Kogetsidis 2009:100-101, after Trosborg 1987).

My general impression is also that the students tend to be verbose, especially when they are less advanced. Verbosity and smaller lexico-syntactical variety have been previously indicated as indicators of lower EFL proficiency. For example, as far as internal request mitigation is concerned, in one of the earliest studies in interlanguage pragmatics on requests, Kasper (1981 after Economidou-Kogetsidis 2009:84) found that her German learners of English exhibited some differences in the use of internal modifiers as compared to English native speakers. The learners employed downtoners less frequently and did not use consultative devices at all. The same applies to Faerch and Kasper's (1989) study of Danish learners of English or German. Other pragmatic interlanguage developmental studies, e.g. Barron (2003), revealed similar patterns, i.e. the underuse of downtoners and overuse of the politeness marker please.

Something that appears to be a vital marker of the students' negative transfer is also their tendency to position the politeness marker please at the beginning or end of the request. The same preference was observed for other requests in the 
discourse completion task. For example, out of 14 instances of please used in request 11, only four were positioned internally (Could you please find two hours for me?) and in request 3 the ratio was 22 to 6 (Szczepaniak-Kozak, in press).

All in all, despite the fact that the study relies on a small sample, its strength lies in its attempt to gain insight into the participating students' interlanguage pragmatical competence. The author realizes, however, that in order to investigate it more fully, more data, and from the later stages of their interlanguage development, are necessary. Regardless, already at this interim stage it has been possible to gather vital conclusions about their acquisition and implications for their classroom instruction.

\section{References:}

Bardovi-Harlig, Kathleen (2001): Evaluating the empirical evidence: Grounds for instruction in pragmatics? In: Rose, Kenneth R. / Kasper, Gabriele (eds), Pragmatics in language teaching. Cambridge, 13-32.

Bardovi-Harlig, Kathleen / Hartford, Beverly S. (1990): Congruence in native and nonnative conversations: Status balance in the academic advising session. In: Language Learning 40(4), 467-501.

Barron, Anne (2003): Acquisition in interlanguage pragmatics. Learning how to do things with words in a study abroad context. Amsterdam.

Blum-Kulka, Shoshana (1987): Indirectness and politeness in requests: Same or different. In: Journal of Pragmatics 11, 131-146.

Blum-Kulka, Shoshana / House, Juliane / Kasper, Gabriele (eds) (1989): Cross-cultural pragmatics: Requests and apologies. Norwood, N.J.

Blum-Kulka, Shoshana / House, Juliane / Kasper, Gabriele (1989): Investigating crosscultural pragmatics: An introductory overview. In: Blum-Kulka, Shoshana / House, Juliane / Kasper, Gabriele (eds), Cross-cultural pragmatics: Requests and apologies. Norwood, N.J., 1-34, Appendix.

Blum-Kulka, Shoshana / Olshtain, Elite (1984): Requests and apologies: A cross-cultural study of speech act realization patterns (CCSARP). In: Applied Linguistics 5(3), 196-213.

Economidou-Kogetsidis, Maria (2009): Interlanguage request modification: The use of lexical/phrasal downgraders and mitigating supportive moves. In: Multilingua 28, 79112.

Ellis, Rod (2003): The study of second language acquisition. Oxford.

Faerch, Claus / Kasper, Gabriele (1989): Internal and external modification in interlanguage request realization. In: Blum-Kulka, Shoshana / House, Juliane / Kasper, Gabriele (eds), Cross-cultural pragmatics: Requests and apologies. Norwood, N.J., 221-247.

Halliday, Michael A. K. / Hasan, Ruqaiya (1985): Language, context, and text: Aspects of language in a social-semiotic perspective. Oxford.

House, Juliane / Kasper, Gabriele (1981): Politeness markers in English and German. In: Coulmas, Florian (ed.), Conversational routine: Explorations in standardized communication situations and prepatterned speech. The Hague, 157-185.

Kalisz, Roman (1993): Different cultures, different languages, and different speech acts revisited. In: Papers and Studies in Contrastive Linguistics XXVII, 107-118. 
Kasper, Gabriele / Dahl, Merete (1991): Research methods in interlanguage pragmatics". In: Studies in Second Language Acquisition 13, 215-247.

Kasper, Gabriele / Schmidt, Richard (1996): Developmental issues in interlanguage pragmatics. In: Studies in Second Language Acquisition 18(2), 149-169.

Levenston, Eddie (1971): Over-indulgence and under-representation: Aspects of mother tongue interference. In: Nickel, Gerhard (ed.), Papers in contrastive linguistic. Cambridge, 115-121.

Liu, Jianda (2007): Developing a pragmatics test for Chinese EFL learners. In: Language Testing 24(3), 391-415.

Lubecka, Anna (2000): Requests, invitations, apologies and compliments in American English and Polish. Kraków.

Marcjanik, Małgorzata (2009): Mówimy uprzejmie: Poradnik językowego savoir-vivre’u. Warszawa.

Ogiermann, Eva (2009a): Politeness and in-directness across cultures: A comparison of English, German, Polish and Russian requests. In: Journal of Politeness Research 5, 189216.

Ogiermann, Eva (2009b): On apologising in negative and positive politeness cultures. Amsterdam.

O'Keeffe, Anne / Clancy, Brian / Adolphs, Svenja (2011): Introducing pragmatics in use. London.

Rakowicz, Agnieszka (2009): Ambiguous invitations: The interlanguage pragmatics of Polish English language learners. Saarbrücken.

Rose, Kenneth R. / Kasper, Gabriele (eds) (2001): Pragmatics in language teaching. Cambridge.

Rue, Yong-Ju. / Zhang, Qiao Grace (2008): Request strategies: A comparative study in Mandarin Chinese and Korean. Amsterdam.

Sabaté i Dalmau, Maria / Curel i Gotor, Horténsia (2007): From 'Sorry very much' to 'I'm ever so sorry': Acquisitional patterns in L2 apologies by Catalan learners of English. In: Intercultural Pragmatics 4(2), 287-315.

Selinker, Larry (1972): Interlanguage. In: IRAL 10, 209-231.

Spencer-Oatey, Helen (ed.) (2000): Culturally speaking: Culture, communication and politeness theory. New York.

Sweeney, Emma / Hua, Zhu (2010): Accommodating toward your audience: Do native speakers of English know how to accommodate their communication strategies toward nonnative speakers of English?. In: Journal of Business Communication 47(4), 477-504.

Szczepaniak-Kozak, Anna (in press): The relation between linguistic proficiency and pragmatic appropriateness: A study of Polish learners of English as a foreign language.

Takahashi, Satomi (2001): The role of input enhancement in developing pragmatic competence. In: Rose, Kenneth R. / Kasper, Gabriele (eds), Pragmatics in language teaching. Cambridge, 171-199.

Trosborg, Anna (1987): Apology strategies in native/non-natives. In: Journal of Pragmatics $11,147-167$.

Wierzbicka, Anna (1985): Different cultures, different languages, different speech acts: Polish vs. English. In: Journal of Pragmatics 9(2-3), 145-178 
Wierzbicka, Anna (2005): Cross-cultural pragmatics: The semantics of human interaction. The Hague.

Zhang, Yanyin (1995): Strategies in Chinese requesting. In: Kasper, Gabriele (ed.), Pragmatics of Chinese as native and target language. Honolulu, 23-68. 
